\title{
Right-Making, Reference, and Reduction
}

\author{
Michael Byron \\ Kent State University
}

DOI: $10.2478 /$ disp-2014-0010

BIBLID [0873-626X (2014) 39; pp. 139-145]

\begin{abstract}
The causal theory of reference (CTR) provides a well-articulated and widely-accepted account of the reference relation. On CTR the reference of a term is fixed by whatever property causally regulates the competent use of that term. CTR poses a metaethical challenge to realists by demanding an account of the properties that regulate the competent use of normative predicates. CTR might pose a challenge to ethical theorists as well. Long (2012) argues that CTR entails the falsity of any normative ethical theory. First-order theory attempts to specify what purely descriptive property is a fundamental right-making property (FRM). Long contends that the notion that the FRM causally regulates competent use of the predicate 'right' leads to a reductio. The failure of this argument is nevertheless instructive concerning a point at which ethics and metaethics overlap.
\end{abstract}

\section{Keywords}

Normative property, descriptive property, causal theory of reference, Jackson, Schroeder

\section{Right-making, reference, and realism}

The causal theory of reference (CTR) provides a well-articulated and widely-accepted account of the reference relation. On CTR the reference of a term is fixed by whatever property causally regulates the competent use of that term. CTR poses a metaethical challenge to realists by demanding an account of the properties that regulate the competent use of normative predicates. ${ }^{1}$ For non-naturalistic realists,

${ }^{1}$ Since anti-realists generally deny that moral judgments involve predication,
on their view the semantic value of moral judgments does not involve reference

Disputatio, Vol. VI, No. 39, November 2014

Received: 30/09/2013 Revised: 08/04/2014 Accepted: 30/04/2014 
who assert that normative properties ${ }^{2}$ are non-natural, the puzzle is to account for how non-natural properties might causally regulate anything. Non-naturalists like Shafer-Landau (2003) define normative properties in terms of non-identical concatenations of natural properties, but by denying identity such views threaten to deny that the reference of normative predicates is fixed. Non-naturalists could of course decline the challenge and jettison CTR. Naturalists, by contrast, regard normative properties as natural properties, and would seem to have an easier time accommodating CTR. Cornell realists like Sturgeon (1988) assert that normative properties are natural properties in their own right, and presumably such normative properties are available to play a causal role in reference. Reductive naturalists like Railton (1986) claim that normative properties are reducible to descriptive properties, and the reduction base might regulate competent use.

CTR might pose a challenge to first-order ethical theorists as well. Long (2012) argues that CTR entails the falsity of any normative ethical theory. First-order theory attempts to specify what purely descriptive property is a fundamental right-making property (FRM). Long contends (bracketing his discussion of the possibility of multiple FRM's) that the notion that the FRM causally regulates competent use of the predicate 'right' leads to a reductio. The argument relies on two assumptions, namely:

A1. A purely descriptive property is a FRM only if the moral property of being right exists.

A2. If the moral property of being right exists, then our predicate 'right' refers to it.

By CTR, if a property F causally regulates competent use of the predicate 'right', then 'right' rigidly designates F. By A1 and A2, 'right'

to properties.

${ }^{2}$ I follow the now fairly standard usage of Jackson (1998: 120-121), according to which a normative property is a property that may be ascribed by a normative predicate, and a descriptive property is a property that may be ascribed by a descriptive predicate. For an accessible discussion of Jackson's reductionism, see Streumer 2011. 
refers to and thus rigidly designates the property of being right. It follows that the property of being right is identical to F, and Long claims that this consequence renders the explanation of rightness absurd. Ethical theory postulates a FRM in order to explain the property of being right, but according to Long it is absurd to think that one property might explain another when they are identical. Hence the reductio of the claim that the FRM causally regulates 'right'. And this conclusion poses a dilemma: either there is no FRM, contrary to ethics, or nothing causally regulates 'right', contrary to CTR.

The reductio argument is confused, however, and we can begin to see why by inquiring about the role the FRM plays. By definition, the FRM is a descriptive property such that whatever has it is right, which is to say is such that, given CTR, the FRM regulates competent use of 'right'. Historically, candidates for the FRM have included such properties as maximizing pleasure or agent-neutral value and compliance with the categorical imperative. One way to unpack the notion that the FRM is "right making" is to say that the FRM just is - or constitutes - the property of being right, and that this constitutive fact explains the identity. On this understanding, both A1 and A2 turn out to be unproblematic. A1 is true because, if the FRM is the property of being right, then the property of being right exists. A2 and the identity together imply that 'right' refers to the FRM.

Long's reductio turns on the idea that, if two properties are identical, then it is absurd to think that one property might explain the other. Long (2012: 278) claims that, if the FRM and the property of being right are identical, then "the property that ultimately explains an action's being right [the FRM] just is the property of being right. That is absurd, however: the property that explains an action's being right cannot be identical to the property of being right" (original emphasis). Long's point might be that if the explanandum and the explanans are identical, it is absurd to think that we could have an adequate explanation. Since it is the properties and not the explanatory expressions that are supposed to be identical, this charge cannot be quite right. If the explanation we seek is causal, Long might be claiming that CTR and ethical theory together entail that cause and effect are identical. That would indeed be an absurd suggestion. But the explanation ethical theory seeks is the answer to, "what makes actions right", and this question is not about the cause of rightness so 
much as its constitution.

Long's argument might be a version of Frege's (1892) puzzle about identity: how can we explain the difference in cognitive significance between $a=a$ and $a=b$ ? The former seems uninformative compared to the latter. The terms 'morning star' and 'evening star' refer to the same object. But the statement that 'morning star = morning star' is analytic, whereas the statement that 'morning star $=$ evening star' is not. Frege's solution to this problem invokes his famous distinction between sense and reference. The senses of 'morning star' and 'evening star' differ, but they have the same reference. The difference in sense explains the difference in cognitive significance between 'morning star = morning star' and 'morning star = evening star.' The sameness of reference is a consequence of the identity.

Perhaps it is misleading to view Long's argument in light of the identity of 'morning star' and 'evening star', which after all name an object. Moreover, we do not use the morning star as a causal explanation of the evening star, nor would we say that the morning star constitutes the evening star. The FRM and the property of rightness are properties, not objects. The identity of normative and descriptive properties usually receives attention from reductionists, who argue that they are identical because the one is reducible to the other. Schroeder (2005) urges caution in this project: reductionists who assume, for example, that the set of properties to be reduced and the reduction base are complementary and so disjoint appear to contradict themselves. If we define descriptive properties as nonnormative properties, then asserting that normative properties are descriptive properties seems to entail a contradiction. Instead, he argues, two modes of reduction seem plausible. The first, and the one I will discuss, is that developed in Jackson 1998, according to which normative properties are reducible to descriptive properties because the former constitute a proper subset of the latter. Since Jackson defines descriptive properties as those that can be picked out by descriptive predicates, his reduction, according to Schroeder (2005: 10), "amounts to the claim that normative properties can be picked out by uncontroversially descriptive predicates. This is a perfectly coherent view" (original emphasis).

A view like Jackson's can underwrite an explanatory relation between descriptive properties and the normative properties to which 
they are identical. Ethical theorists seek a FRM that is identical to the normative property of rightness. Suppose value-maximizing is the (descriptive) FRM, and suppose that Jackson is right to think that the normative property of rightness is reducible to a descriptive property. It follows that the properties are identical and that rightness is value-maximizing. Moreover, the descriptive predicate 'value-maximizing' picks out the normative property of rightness. Far from being impossible or absurd as Long claims, that result would be informative and illuminating, since it would explain why maximizing value is right. The identity of value-maximizing with rightness accommodates Long's assumptions A1 and A2 because the property of being right exists and the predicate 'right' refers to it. On this view 'right' refers to the property of rightness, which is also the property of maximizing value. The view's explanatory power lies in linking the descriptive predicate to the normative property, not in anything mysterious about the identity. And if Jackson is right, the fact that the descriptive predicate 'value-maximizing' and the normative predicate 'right' both refer to the same property should hardly be surprising: his thesis is that normative properties are a subset of descriptive properties, and thus that all of them may be picked out by both normative and descriptive predicates. ${ }^{3}$

The explanation of rightness in terms of the FRM emerges from linking those predicates in certain systematic ways justified by ethical theory. At issue here could be the sense in which the FRM is "right making", where the FRM constitutes rightness. The relation of the FRM to rightness represents a point of contact between ethics and metaethics. Ethics has an interest in the identity between the FRM and rightness in virtue of its need to explain rightness in terms of the FRM. Such an explanation is useful both practically, by pro-

\footnotetext{
${ }^{3}$ Schroeder's preferred mode of reductionism does not offer a further alternative to thinking that the identity of normative and descriptive properties must be explanatorily inert. He proposes that we could, for example, reduce normative to descriptive properties through analysis rather than, as Jackson does, by regarding one as a subset of the other. Schroeder regards this difference as a strength, since it enables him to define descriptive properties as non-normative and yet reduce the normative to the descriptive without contradiction. As intriguing as it is, his view would not yield property identity, which is the sticking point in Long 2012. For more detail, see Schroeder (2005: 10ff.).
} 
viding guidance to decision making, and epistemically, by offering resources for justifying action. That is the ethical perspective on the question, 'what makes an action right?' Metaethics has an interest in the identity between the FRM and rightness in virtue of its need to explain the semantic value of the predicate 'rightness'. The ethical issue is a question in the metaphysics of morality, since it requires accounting for the sense in which the FRM constitutes rightness. The metaethical issue is a question in the semantics of moral language, since it deploys the identity of the FRM and rightness in order to explain the semantic values of the corresponding predicates.

This point of overlap is important in the context of recent discussions concerning the relation of ethics and metaethics. Indeed, Dworkin (2011) argues vigorously in favor of collapsing the distinction altogether because, as Kalderon (2013) points out, he thinks that all significant metaphysical questions ought properly to be conceived as first-order and substantive. The murky metaethical waters of constructivism are beyond our scope here, but it is an interesting question whether some similar argument shows that all significant semantic questions ought likewise to be conceived as first-order and substantive. That would be the relevant point to establish with relation to the identity of the FRM with rightness. I can only gesture at a negative answer: Putnam's (1976) discussion of the synthetic identity of 'temperature' with 'mean molecular kinetic' energy presupposes a result in physics, but it would be a stretch to conclude that it is therefore a contribution to physics. I suspect that a similar conclusion might be reached with regard to the semantics of rightness given CRT. Though CRT presupposes the identity of the FRM with rightness, the account of the semantic values of the corresponding predicates might not thereby constitute a contribution to ethical theory. At least, we should await an argument that shows why it should do so. ${ }^{4}$

Michael Byron

Philosophy Department Kent State University PO BOX 5190

\footnotetext{
${ }^{4}$ I am grateful to an anonymous reviewer, whose suggestions and comments substantially improved this paper.
} 
Kent OH 44242-0001

USA

mbyron@kent.edu

\section{References}

Dworkin Ronald. 2011. Justice for Hedgehogs. Cambridge, MA: Harvard University Press.

Frege, Gottlob. 1892.Über Sinn und Bedeutung. Zeitschrift für Philosophie und philosophische Kritik 100: 25-50. Translated as On Sense and Reference by M. Black in Translations from the Philosophical Writings of Gottlob Frege. Edited by P. Geach and M. Black. Oxford: Blackwell, third edition, 1980.

Kalderon, M. A. 2013. Does metaethics rest on a mistake? Analysis 73: 129-138. Jackson, Frank. 1998. From Metaphysics to Ethics. Oxford: Clarendon Press.

Long, Justin. 2012. Right-Making and Reference. American Philosophical Quarterly 49: $277-280$.

Putnam, Hilary. 1979. On Properties. In Philosophical Papers: Vol. 1, Mathematics, Matter and Method. Cambridge: Cambridge University Press, 305-322.

Railton, Peter. 1986. Moral Realism. Philosophical Review 95: 163-207.

Russell, Bertrand. 1905. On Denoting. Mind 14: 479-493.

Schroeder, Mark. 2005. Realism and Reduction: the Quest for Robustness. Philosophers' Imprint 5: 1-18.

Shafer-Landau, Russ. 2003. Moral Realism: A Defence. Oxford: Oxford University Press.

Streumer, Bart. 2011. Are Normative Properties Descriptive Properties? Philosophical Studies 154: 325-348.

Sturgeon, Nicholas. 1988. Moral Explanations. In Essays on Moral Realism. Edited by G. Sayre-McCord. Ithaca and London: Cornell University Press, 229-255. 